\title{
Screening for Congenital Hypothyroidism-Time to Raise the Bar?
}

\author{
Anurag Bajpai ${ }^{1,2}$ \\ Received: 10 August 2021 / Accepted: 13 August 2021 / Published online: 21 September 2021 \\ (c) Dr. K C Chaudhuri Foundation 2021
}

Screening for congenital hypothyroidism is essential to prevent the deleterious effect of the disorder. The European Society for Pediatric Endocrinology (ESPE) and American Academy of Pediatrics guidelines have been widely used for interpreting neonatal screening results [1, 2]. Consideration for regional factors and resource availability is mandatory to allow widespread implementation of the screening program. Indian Society for Pediatric \& Adolescent Endocrinology (ISPAE) has recently provided guidance for screening, evaluation, and management of congenital hypothyroidism $[3,4]$. These guidelines differ from the ESPE guidelines in the TSH action thresholds. The impact of this change on the diagnostic value of the screening strategy has not been studied.

Venugopalan et al. report, in this issue of the journal, their experience on the utility of ISPAE guidelines in identifying congenital hypothyroidism in a high-risk neonatal unit [5]. The retrospective chart review of 8064 neonates showed that the increase in screening TSH cutoffs as per the ISPAE guidelines decreased the detection rate of congenital hypothyroidism from $88.0 \%$ (73 out of 83 ) to $43.3 \%$ (36 of 83). This, however, did not impact the detection of congenital hypothyroidism, as all the 47 cases missed by the cutoff met the guidelines for rescreening and would have been identified on retesting. This is related to the "high risk" nature of the setting, as indicated by the need for retesting in $20.1 \%$ (1622 of 8064 ) neonates. The authors conclude that the upward revision of the screening TSH threshold is expected to lower the number of neonates recalled (increased specificity) while not missing cases (preserved sensitivity).

The study provides insights into the impact of revised cutoffs for neonatal screening. A disproportionately high

Anurag Bajpai

dr_anuragbajpai@yahoo.com; dr_anuragbajp1@ @otmail.com

1 Department of Pediatric Endocrinology, Regency Center for Diabetes, Endocrinology \& Research, Kanpur, Uttar Pradesh 208001, India

2 Fortis Memorial Research Institute, Gurgaon, Haryana, India representation of at-risk neonates and a prevalence of hypothyroidism ( 1 in 97) limit the generalizability of the study in the community. The retesting of 1 in 5 neonates in the study allowed detection of over half the neonates with congenital hypothyroidism missed due to revised TSH cutoffs. The diagnostic accuracy of revised TSH cutoff without the retesting safety net in the community remains unclear. This study confirms the applicability of ISPAE guidelines in an at-risk setting; the validation in the community awaits more extensive community studies.

\section{Declarations}

Conflict of Interest None.

\section{References}

1. Léger J, Olivieri A, Donaldson M, et al. ESPE guidelines on screening, diagnosis, and management of congenital hypothyroidism. J Clin Endocrinol Metab. 2014;99:363-84.

2. Rose SR, Brown RS, Foley T, et al. Update newborn screening and therapy for congenital hypothyroidism. Pediatrics. 2006;117:2290-303.

3. Sudhanshu S, Riaz I, Sharma R, Desai MP, Parikh R, Bhatia V. Newborn screening guidelines for congenital hypothyroidism in india: recommendations of the Indian Society for Pediatric and Adolescent Endocrinology (ISPAE) - Part II: imaging, treatment, and follow-up. Indian J Pediatr. 2018;85:448-53.

4. Desai MP, Sharma R, Riaz I, Sudhanshu S, Parikh R, Bhatia V. Newborn Screening Guidelines for Congenital Hypothyroidism in India: recommendations of the Indian society for Pediatric and Adolescent Endocrinology (ISPAE) - Part I: Screening and Confirmation of Diagnosis. Indian J Pediatr. 2018;85:440-7.

5. Venugopalan L, Paranjyothi S, Sankaran A, Prasad HK, Murugesan G, Shanmughasundaram R. Utility of the New Indian Society of Paediatric and Adolescent Endocrinology (ISPAE) guidelines for congenital hypothyroidism screening in a high-risk unit. Indian J Pediatr. 2020. https://doi.org/10.1007/s12098-020-03555-x.

Publisher's Note Springer Nature remains neutral with regard to jurisdictional claims in published maps and institutional affiliations. 